\title{
Moderating Effect of Environmental Factors on eHealth Development and Health Outcomes: A Country-Level Analysis
}

\author{
Supunmali Ahangama and Danny Chiang Choon Poo \\ Department of Information Systems, School of Computing, National University of Singapore, \\ 13 Computing Drive, Singapore 117417 \\ supunmali@comp.nus.edu.sg, dannypoo@nus.edu.sg
}

\begin{abstract}
This cross-national study examines how the relationship between national eHealth initiatives and health outcomes are contingent on (1) macroeconomic stability; (2) GDP per capita; and (3) institutions. Resource Based View's (RBV) resource complementary perspective and literature on Information Technology and health outcomes are used as the guiding theoretical framework. Publicly available archival data from more than 50 countries are gathered to understand the moderating effect. Health outcomes are measured through Infant Survival Rate (ISR). The results indicated that there is no direct effect of eHealth initiatives on health outcomes; however, eHealth initiatives interact with above three contingencies affecting health outcomes. Macro-economic stability moderated the relationship between eHealth development and health outcomes positively. GDP per capita and institutions moderated the relationship of eHealth development and health outcomes in a negative direction. Implications of the findings for theoretical discourse of the resource complimentary perspective and future research are discussed in this paper.
\end{abstract}

Keywords: eHealth, Infant Survival Rate, resource complementary perspective.

\section{Introduction}

eHealth can be recognized as an essential tool in ensuring a safer, efficient and sustainable healthcare delivery around the world[1-4]. Use of eHealth will facilitate the provision of a more patient centered care[5] outside the traditional environment which could be a shift of focus from general practitioners office or from hospitals. According to WHO[4], eHealth is the use of information and communication technologies (ICT) for health. This could be for treating patients, conducting research, educating the healthcare personnel, tracking diseases and monitoring public health. eHealth is a field that has become prominent within the last decade and can be identified as a rapidly growing area. Though electronic health records (EHR) is not eHealth, EHR is the heart of eHealth. eHealth is broader and a larger group of stakeholders could be reached through this technology. eHealth resources will be managed or used by medical staff, patients, government policy makers, researchers, general public etc., dispersed in 
different geographical locations. Usage of eHealth will be critical in transforming the healthcare sector into a new level. However, most of the Information Technology (IT) applications are developed targeting administrative and financial transactions rather than to support clinical care[3].

Introduction of eHealth tools to healthcare services is enormously challenging due to numerous factors varying from common factors such as limited financial support available to much more serious factors like, lack of a legal framework to protect the privacy of users. Ensuring the privacy of the patients is a major concern in using eHealth in healthcare industry. Lack of adequate measures to ensure the privacy of patients may reduce the acceptability of this new technology, eHealth by many patients. Such a low acceptance by the major stakeholders group (patients) may limit the potential of achieving the expected benefits of eHealth and it may be detrimental. Moreover, IT is likely to cause digital divide where people with IT access will get a better service compared to people who do not have IT access.

While most of the studies that have been carried out at country-level have mainly considered the contribution of IT to economic growth[6], only a very few countrylevel studies had been carried out to understand the contribution of IT investments on better health outcomes. In reviewing existing literature, we found that findings of prior studies that examined the relationship between IT expenditure and health outcomes have shown mixed results and had merely identified possible negative consequences related to EHR usage[7]. Moreover, these authors have focused on overall IT expenditure of a nation rather than on specific eHealth expenditure or eHealth initiatives. Thus, assessing the relationship between eHealth initiatives and health outcomes can be considered as a key research gap to be answered.

We address this, by using the resource complementary perspective of Teece[8] and propose that the relationship between eHealth development and health outcomes is moderated by national environmental factors, namely, (1) institutional; and (2) economic factors (GDP per capita and macro-economic stability). Though there can be numerous factors affecting eHealth development and health outcomes (quality and safety), we consider that the institutional factors and economic factors are the key factors capable of affecting any development strategy and its outcomes in any country [9]. While GDP and macro-economic stability indicate the availability of financial resources for implementation of eHealth, institutional factors indicate the capability of individuals and legal framework in health care institutions to generate better health outcomes.

Health outcomes will be measured using Infant Survival Rate (ISR), which is a parallel measure to Life Expectancy Rate (LER) more commonly used as the prime indicator of quality of a healthcare system[10]. These complementary assets will be modeled using archival data of 55 countries. These 55 countries were selected based on the fact that data on all the necessary variables for the study were available only for these countries and a number of countries had to be excluded due to nonavailability of data for one or more variables.

RQ: How do a nation's complementary assets (macro-economic stability, GDP per capita and institutions) interact with national eHealth initiatives in predicting its health outcomes? 
This paper is organized as follows. Theoretical framework is briefly explained in section (1.1) and descriptions on hypothesis development and research design are dealt with in sections (2) and (3). Sections (4), (5) and (6) deal with analysis and results, discussion and conclusion respectively.

\subsection{Theoretical Framework}

The concept of complementary assets introduced by Teece[8], describes that for commercializing a new product profitably, a firm needs access to complementary assets (manufacturing and distribution facilities) in a favorable manner[11]. Complementary assets are resources or capabilities that allow firms to capture the profits associated with a strategy, technology or innovation[12]. Even though, competitors can duplicate and launch the same new product they will not be able to get a competitive advantage if they do not get access to complementary assets possessed by the producer. Based on Resource Based View (RBV)[13], complementary assets can be categorized into two different areas as resource copresence view and resource channeling view. Resource co-presence view explains that a resource can be considered to be a complementary asset if its presence increases the value or outcome of another resource. This is also known as interaction perspective. Resource channeling view explains that when resources are used in mutually reinforcing manner, complementary assets are formed[14]. Thus, former can be applied into our study to understand why certain countries have better health outcomes compared to some other countries[10]. Complementary assets will be helpful in achieving high health outcomes from IS innovations related to healthcare. Rather than developing and deploying eHealth tools itself, it is important to understand the complementary assets that could provide a better utility. Moderating variables (macro-economic stability, GDP per capita and institutions[6, 15]) used in this study will be complementary assets that will enhance the relationship between eHealth development and health outcomes.

Many studies have been carried out on the impact of IT investment on quality and safety of healthcare system[16-18]. There had been endorsements from World Health Assembly by passing an eHealth resolution (WHA 58.28) in 2005 for eHealth implementation and development as a means for improving healthcare. Stroetmann and others[18] have found economic benefits of implementing eHealth considering 10 sites in Europe. In reviewing publications on the impact of eHealth on the quality and safety of health care between 1997 and 2010, Black et al.[17] have found only limited evidence indicating achievement of expected benefits and have even found some situations where implementation of eHealth leading to detrimental effects. Particularly, the reviewers have not found sufficient evidence showing improvement in patient outcomes associated with these technologies, though large-scaled projects have been funded and deployed to support eHealth implementations.

It is reported in literature[10] that IT investments influence life expectancy. However, these authors have used the overall IT expenditure for a country as an attribute in their study, rather than considering the ICT expenditure specifically related to healthcare and has identified it as a limitation in carrying out their research. They have identified that the three mechanisms-information integration, workflow coordination and collaborative planning via ICT can influence health outcomes. 
According to them, adequate investments on these three mechanisms and collective application of them (eHealth) will lead to positive health outcomes.

\section{Hypothesis Development}

Better outcomes can be obtained by improving the quality of healthcare system by infusing ICT. It is evident from literature that a more efficient and safer medical service could be provided by using health IT. According to Mithas et al.[10] overall life expectancy of a country can be improved based on the IT expenditure of a country. The authors have identified Information integration, Workflow coordination and Collaborative Planning as the three main areas of IT, which could influence the healthcare sector. Information integration is consolidation of diverse information sources (both semi structured and unstructured data) into structured data (and information). Information integration will allow access to information in 24/7 as and when required for intra and inter hospital activity coordination and management. Thus, better judgments can be made through integration of data from different sources. Workflow coordination is automation of the activities in the care value chain. For example, efficient distribution of drugs avoiding scarcities and endangering patients could be achieved through workflow coordination. Collaborative planning allows effective cooperation between different levels in a hospital.

There is a dearth of published literature on the influence of national environmental factors (moderating variables) on eHealth development and standard of health (Infant Survival Rate, ISR) in a country. Health Standards is a part of Human Development Index (HDI) where life expectancy is used as an indicator for health standards[19].

\subsection{Moderating Effect of Macro-economic Stability}

Macro-economic stability of a country can be maintained through a low inflation rate with declining budget and trade deficits[15]. The stability of the macro-economic environment is important for success in carrying out eHealth initiatives. With stable macro-economic conditions advanced countries in the world are more likely to implement eHealth effectively as they have done with e-government development[20]. Though, macro-economic stability may not directly affect the overall life expectancy, economically unstable countries over burden with debts may not invest in ICT for healthcare. When the macro-economy of a country is unstable, government would not be able to provide services in an efficient manner[15]. High inflation may lead governments to provide the people with only the essential services even in the health sector rather than attempting on providing them with value added services or preventive care.

Healthcare expenditure is escalating in many countries. In the USA, healthcare expenditure was expected to double between 1998 and 2007. Thus, the governments should be in a position to address the escalating costs. Through eHealth, people can access health services via internet to reduce costs[19] and to improve the survival rate or longevity of life. The following hypothesis was established in identifying the major 
role played by macro-economic stability of a country in developing and in implementing its IS innovations relevant to healthcare.

H1: The relationship between eHealth development in a country and its Infant Survival Rate is moderated by macro-economic stability. The relationship becomes stronger when the stability of macro economy is high and becomes weaker when macro-economic stability is low.

\subsection{Moderating Effect of GDP Per Capita}

GDP per capita is an indication of a country's wellbeing and is used to measure the economic development of a country. It has been noted that healthcare expenditure as well as health concerns increase with a nation's economic development[10, 21]. The introduction and use of eHealth tools will mainly depend on the financial support available. If it is accessible only to those who can pay, the benefits of eHealth will be low for poorer sections of the population in less developed regions, and will only be a burden to the public health systems. In addition, financial constraints will play a major role in ensuring the privacy of patients too, which is a major concern related to eHealth. For example, additional financial support will be required to train healthcare workforce or to deploy sophisticated health information safety measures.

It has been found that IT has different impacts depending on whether the particular country is a developing or a developed country. Moreover, it has been identified that higher income leads to increased use of eHealth[19, 22]. Thus low-income groups in poorest countries who are inherently more susceptible to preventable diseases are experiencing the lowest contact with eHealth tools. Having access to eHealth will facilitate access to health information and preventive measures. Mothers will use advice on health nutrition and fitness or on vaccinations to prevent many fatalities of children due to preventable causes. Thus, we postulate that better GDP per capita will allow higher improvement in ISR via access to eHealth.

H2: The relationship between eHealth development in a country and its Infant Survival Rate is moderated by GDP per capita. The relationship becomes stronger when GDP per capita is high and becomes weaker when GDP per capita is low.

\subsection{Moderating Effect of Institutions}

According to the global competitive index, the institutional environment shapes up the framework within which individuals, firms, and governments interact. It also focuses on how societies share the benefits and bear the burden of development strategies. Thus, factors such as intellectual property rights, ethics and corruption, undue influence, government inefficiency and security have been considered in defining the institutional environment[15]. In the usage of ICT in healthcare, it is important to ensure the transparency in handling patient records while maintaining privacy of patients. Thus, it should be possible to maintain good governance and maintain ethical practices followed in healthcare industry relying on eHealth. 
Many political and policy amendments will be required to integrate the eHealth tools to daily operations of healthcare industry smoothly. Importantly there should be a legal framework to facilitate secure transfer of information between various stakeholders even across different geographical boundaries. The transfer of information could be varying from communication between the physician and the patient to sharing of research findings. Organization for Economic Co-operation and Development (OECD) has highlighted in its 2010 report, the importance of having a new legal framework for sharing medical information to improve the efficiency in healthcare service. They have identified this as a challenge even in world's most advanced countries.

We can hypothesize, that when there is better structure of institution, higher benefits of eHealth can be achieved to increase the ISR.

H3: The relationship between eHealth development in a country and its Infant Survival Rate is moderated by institutions. The relationship becomes stronger when the quality of institutions is high and becomes weaker when quality of institutions is low.

\subsection{Control Variables}

Four control variables (excluding theoretical constructs of concern) that could explain the variance of dependent variable (ISR) are considered. Firstly, we control number of hospital beds per 10,000 of the population as it is an indicator of quality of healthcare infrastructure of a country[10]. According to World Health Statistics by WHO, number of hospital beds are composed of beds available in public, private, general and specialized hospitals. Secondly, as a proxy for healthcare service, we controlled physician density and nurse and midwife personnel density. These values are taken from the World Health Statistics Report 2010 of WHO. It is the amount of health workforce per 10,000 population[10]. In addition, effect of ICT infrastructure is controlled and the index is computed considering number of PCs, Internet users, main telephone lines, mobile phones and broadband users per 100 people. The data are obtained from UN e-Government Survey Report 2008.

\section{$3 \quad$ Research Design}

A cross sectional analysis of 55 countries (See Appendix) is used for testing the hypothesis. 2011 is used as the base year (for dependent variable) and values for all the other constructs are captured in previous years[10]. Archived (retrospective) data are used as it is impossible to collect primary data within the available resource constraints and also because archived data will allow reproducibility with ease and are generalizable[23]. In addition common method bias could be avoided as data are gathered from different sources[24]. The main data sources are (1) World Health Statistics 2011[25] and 2010; (2) UN e-Government Survey report 2008[26]; (3) WEF Global Competitiveness Report 2008-2009[15]; (4) Digital Planet 2008[27]; and 
(5) Global e-Health Survey Results 2009 of WHO (and country profiles developed based on 2009 survey results)[4]. These reports are considered to be reliable sources and many authors have used these data in their research. For example, Digital Planet Report is used by Mithas et al. [10] and Bankole et al. [28] to study the impact of IT expenditure on quality of healthcare system of a country (using WHO statistics). In addition, Global Competitiveness Report and e-Government Survey Report are used by many researchers to apply into various areas[20, 29, 30].

These data collecting organizations follow rigorous procedures to maintain the reliability and validity of these data. To ensure quality of these data, for example, (1) data are collected only from CEOs or equivalent high ranked officials; (2) respondents can answer in their preferred language; (3) administration of survey is done in several modes (face-to-face, telephone and online interviews or surveys); and (4) a careful editing of data is performed before aggregating to get country-level data[15].

\subsection{Operationalization of Constructs}

Many previous studies[10, 31] used LER, to measure the quality of healthcare systems. However, as suggested by Bankole et al. [28], LER will be more useful in considering the impact over a long term. To evaluate the impact of eHealth on LER, it may require a longer period to be considered. However, the impact of eHealth on Infant Mortality Rate (IMR), a parallel measure to LER can be detected in a shorter period of time compared to LER. LER is the average number of years of life remaining at a given age. According to World Population datasheet, LER at birth (most commonly used) is "the average number of years a newborn is expected to live under current mortality levels". IMR is the number of infant deaths per 1000 live births. ISR is computed by subtracting IMR from 1000 (ISR=1000-IMR). IMR values are obtained from the WHO World Health Statistics 2011.

As an index for eHealth is not available in published literature, a new construct is developed using (1) ICT expenditure on healthcare (for computer hardware, software and services) by a country for 2008 (data obtained from Digital Planet 2008); (2) whether eHealth policy is implemented; and (3) whether ICT capability is provided to healthcare personnel and students (related to healthcare). The data for latter two items are obtained from WHO ATLAS country profiles developed based on Global eHealth Survey Results 2009. The new index is used to indicate the level of eHealth development in a country. This measure is developed based on methods used in the development of similar measures like e-Business development (whether of businesses use internet for buying and selling goods)[32].

Macro-economic stability index is taken from WEF Global competitiveness report 2008-2009[15]. This is composed of (1) government surplus/ deficit; (2) national savings rate; (3) inflation; (4) interest rate spread; and (5) government debt. GDP per capita is also adopted from Global competitiveness report 2008-2009. GDP per capita will be used to represent the economic prosperity of a country. Similarly, Institutions index is obtained from the same report mentioned above and it is developed using (1) intellectual property rights; (2) ethics and corruption; (3) undue influence; 
(4) government inefficiency; and (5) security. These three indices had been used in past studies to understand the e-government development[20].

\section{$4 \quad$ Analysis and Results}

\subsection{Descriptive Statistics}

It is evident from Table 1, that most correlations among variables are significant at $\mathrm{p}<0.001$. The correlation among independent and moderating variables are less than the threshold value of $0.8[33,34]$ except for between institutions and ICT infrastructure $(\mathrm{r}=0.82)$. Although this indicates a potential for multi-collinearity, our use of a robust method of moderated multiple regression to test the hypotheses generally ease any undue influences[35, 36]. In addition, since these variables measure different parameters and are used as standard measures (used as two distinct pillars in computing the global competitive index) of WEF global competitiveness report[15], the high correlations may not gravely impinge on the results. Nevertheless, we performed the diagnostic statistical collinearity tests to measure variance inflation factor (VIF). VIF is used to evaluate the impact the other independent and moderating variables have on the standard error of a regression coefficient[19, 35]. If VIF is below 10, then it can be considered as an absence of serious multi-collinearity issue. The variable ICT infrastructure is having a VIF of 5.2, thus, it is not removed as it is below the threshold value of 10 . All the other variables show VIF values less than 5 indicating non-existence of multi-collinearity.

Table 1. Descriptive statistics and coorelations

\begin{tabular}{|c|c|c|c|c|c|c|c|c|c|c|c|c|}
\hline Variables & $M$ & $S D$ & & & & & & & & 7 & 8 & 9 \\
\hline $\begin{array}{l}\text { 1.Physicians } \\
\text { density }^{\mathrm{a}}\end{array}$ & 2.80 & 1.02 & & & & & & & & & & \\
\hline $\begin{array}{l}\text { 2.Nurses } \\
\text { density }^{\mathrm{a}}\end{array}$ & 3.38 & 1.33 & 46 & & & & & & & & & \\
\hline 3.Hospital beds $\mathrm{s}^{\mathrm{a}}$ & 3.35 & 0.85 & 73 & 34 & & & & & & & & \\
\hline $\begin{array}{l}\text { 4. ICT } \\
\text { Infrastructure }\end{array}$ & 0.38 & 0.25 & 69 & 52 & 65 & & & & & & & \\
\hline 5. eHealth & 0.76 & 0.20 & 66 & 37 & 56 & 61 & & & & & & \\
\hline 6. Institutions & 4.47 & 0.96 & 50 & 52 & 41 & 82 & 53 & & & & & \\
\hline 7. MSI & 5.03 & 0.82 & 40 & 38 & 28 & 53 & 41 & 52 & & - & & \\
\hline $\begin{array}{l}\text { 8. GDP per } \\
\text { Capita }^{a}\end{array}$ & 12.76 & 1.52 & 34 & 12 & 25 & 33 & 57 & 21 & 30 & & - & \\
\hline 9. ISR $^{\mathrm{a}}$ & 6.89 & 0.02 & 70 & 43 & 68 & 66 & 53 & 52 & 41 & 30 & & - \\
\hline
\end{tabular}

$\mathrm{N}=55$; $\mathrm{M}=$ mean; $\mathrm{SD}=$ Standard deviation; MSI=Macro-economic Stability; All correlations equal or greater than 0.25 are statistically significant at $\mathrm{p}<0.05$; Decimal points omitted for correlations; ${ }^{a}$ Log transformed variables

Note: See page 7 for description of variables 


\subsection{Hypothesis Testing}

Moderated multiple regression[37, 38], an established method is used in many studies to test interaction effect. As per Frazier and others[37], continuously measured predictor and moderator variables involved in the regression equations are standardized (Z-scoring). Since independent variables and moderator variables are highly correlated with the interaction term, centering or standardization will reduce the multi-collinearity problem[39, 40]. Moreover, z-scoring makes it easy to compute with available standard packages, to plot significant moderation effects and also to interpret the effect of interaction effects[40]. Hierarchical multiple regression equation is structured in such a way that variables are entered into the model in series of steps as presented in Table 2 . Firstly control variables, secondly predictor variables and the moderator variables (coded or standardized variables) and thirdly the product terms are entered into the equation. All the individual variables used to create interaction terms should be included in the model before the interaction terms[37]. Furthermore, it is important that all the interaction terms are entered simultaneously, thus, their effects can be assessed at the presence of other interactions [38, 39].

$\mathrm{R}^{2}$ value of 0.71 and adjusted $\mathrm{R}^{2}$ value of $0.635(\mathrm{~F}=9.554, \mathrm{p}<0.001)$ indicates that the overall model is useful in explaining the variance in ISR. The change in $R^{2}$ value between step 2 and 3 as shown in Table 2, is $0.112(\mathrm{~F}=5.525, \mathrm{p}<0.01)$. Thus, it is possible to interpret the outcome in testing the moderation effects. Though, there is no direct effect of eHealth development on ISR, it can be noted that there is significant moderating effect and eHealth development interact with moderator variables to affect ISR. The relationship between eHealth development and ISR is contingent on macro-economic stability $(\beta=0.337, \mathrm{p}<0.05)$ and the direction of interaction pattern for eHealth development and standard of health is consistent with the initial prediction. Thus, $\mathrm{H} 1$ is supported. The relationship between eHealth development and ISR is contingent on GDP per capita $(\beta=-0.418, \mathrm{p}<0.01)$. However, the direction of interaction pattern for eHealth development and ISR is contrary to our prediction. Hence, we can conclude that $\mathrm{H} 2$ is not supported. Then the relationship between eHealth development and ISR is contingent on institutions $(\beta=-0.386, p<0.01)$ in the negative direction indicating that $\mathrm{H} 3$ is not supported.

We did plot interaction effects (Figure 1-3) to determine whether the interactions (that are significant) confirm to the proposed direction of interactions as we hypothesized. Moreover, a slope analysis is performed to evaluate whether the gradient differs from zero[37, 38, 40]. Figure 1 presents the disordinal (crossover) interaction of macro-economic stability on the relationship between ISR and eHealth development. When a simple slope analysis is performed on the effect of macroeconomic stability on the relationship of ISR with eHealth development, it revealed that when the macro-economic stability is high the relationship of ISR and eHealth development was positive and significant $(\mathrm{t}=13.46, \mathrm{p}<0.001)$. When the macroeconomic stability is low, the relationship is negative and significant $(\mathrm{t}=-19.81$, $\mathrm{p}<0.001)$. 
Table 2. Regression results

\begin{tabular}{|c|c|c|c|}
\hline \multicolumn{4}{|c|}{ Moderated Multiple Regression Steps } \\
\hline & \multicolumn{3}{|c|}{$\beta^{\mathrm{a}}$} \\
\hline & Step 1 & Step 2 & Step 3 \\
\hline \multicolumn{4}{|c|}{ Controls } \\
\hline Hospital beds & $0.288^{*}$ & $0.326^{*}$ & $0.298 *$ \\
\hline Physicians density & $0.292 *$ & 0.293 & -0.002 \\
\hline Nurses density & 0.067 & 0.067 & 0.043 \\
\hline ICT infrastructure & 0.242 & 0.242 & $0.493 *$ \\
\hline \multicolumn{4}{|c|}{ Main Effect } \\
\hline eHealth & & -0.60 & -0.231 \\
\hline Macro-economic Stability & & 0.066 & -0.039 \\
\hline GDP per Capita & & 0.062 & 0.152 \\
\hline Institutions & & 0.098 & 0.027 \\
\hline \multicolumn{4}{|c|}{ Interaction Effect } \\
\hline eHealth*Macro-economic Stability & & & $0.337^{*}$ \\
\hline eHealth*GDP per Capita & & & $-0.418^{* *}$ \\
\hline eHealth*Institutions & & & $-0.386^{* *}$ \\
\hline $\mathrm{R}^{2}$ & 0.589 & 0.598 & 0.710 \\
\hline Adjusted $\mathrm{R}^{2}$ & 0.556 & 0.528 & 0.635 \\
\hline $\mathrm{F}$ & $17.922 * * *$ & $8.543 * * *$ & $9.554 * * *$ \\
\hline $\mathrm{R}^{2}$ Change & - & 0.009 & 0.112 \\
\hline F Change & - & 0.246 & $5.525 * *$ \\
\hline \multicolumn{4}{|c|}{${ }^{\mathrm{a}}$ The beta values reported are based on standardised coefficients } \\
\hline$* \mathrm{p}<0.05 \quad * * \mathrm{p}<0.01 \quad * *$ & tailed) & & \\
\hline Note: See page 7 for description of $v$ & & & \\
\hline
\end{tabular}




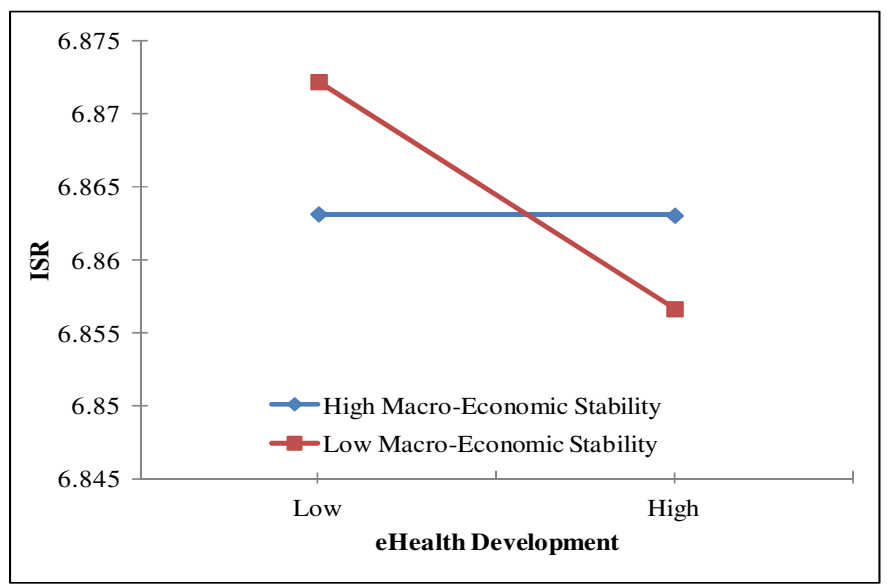

Fig. 1. Moderating influence of macro-economic stability on relationship between eHealth development and ISR (healthcare standard)

Figure 2 shows the disordinal interaction of GDP per capita on the relationship between ISR and eHealth development. When a simple slope analysis is performed on the effect of GDP per capita on the relationship of ISR with eHealth development, it revealed that when the GDP per capita is high the relationship of ISR and eHealth development was negative and significant $(\mathrm{t}=-3.02, \mathrm{p}<0.01)$. However, when the GDP per capita is low, the relationship was positive and non-significant ( $t=0.89$, n.s.). Interestingly, this indicates that the positive relationship of interaction of GDP per capita and eHealth development on ISR occurs only at low GDP per capita. This finding will be discussed in detail in the next section.

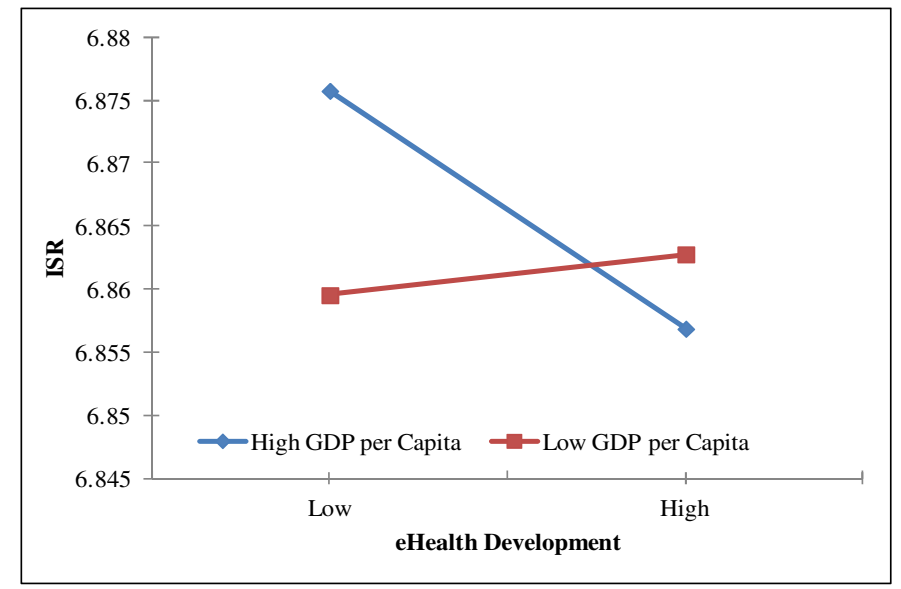

Fig. 2. Moderating influence of GDP per Capita on relationship between eHealth development and ISR (healthcare standard) 


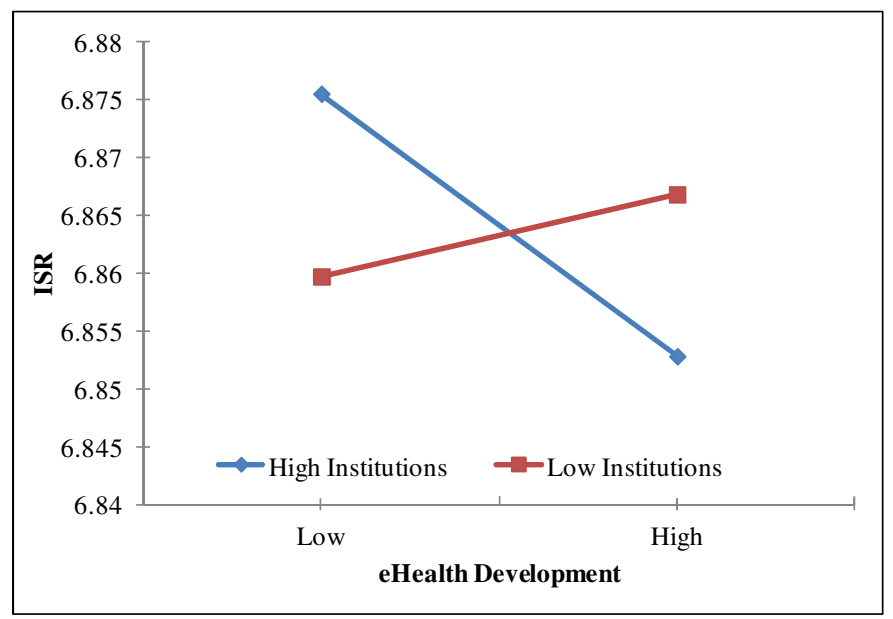

Fig. 3. Moderating influence of institutions on relationship between eHealth development and ISR (healthcare standard)

\section{Discussion}

Through this research it was expected to understand and assess the environmental factors that affect the relationship between eHealth development and standard of health (ISR). Through the analysis carried out using country-level data, it is identified that macro-economic stability plays a significant role in improving ISR in the presence of eHealth. That is, if the macro-economy is not stable, a country will not be able to achieve high health standards through eHealth development. Thus, the expected benefits from eHealth may not be achieved unless there is macro-economic stability in a country.

However, eHealth development may not affect ISR, at higher levels of institutions (moderated in negative direction). Firstly, having a high level of institutional framework, may burden the deplorers and users and thus, they may not be willing to follow on a cumbersome process and may even reject it. Secondly, this may be possibly due to the maintenance of many eHealth informative websites without any legitimate responsibility to the content provided. Thus, even if there is a high level of institutional framework, a lack of assurance on the validity of content may reduce user confidence in such websites and hence their acceptance. Another fact is that though, many countries have introduced eHealth policies, very few countries (even among advanced nations) such as Singapore and UK[4] have implemented the eHealth policy fully. As such, in most of these countries, the true benefits may not be possible to achieve until a sound legal framework is created. For example, privacy and ethical issues in handling patient data may have not been completely answered, and such partial implementation could be detrimental rather than non-implementation of policies. Further, it has been found that even though there are effective policies, it is important to improve the perception of healthcare workforce if the expected benefits are to be achieved. For example, a medical practitioner may alter the concerns on privacy, depending on where they are working (private or government hospital)[4]. 
According to this analysis, eHealth development may not affect ISR, at higher levels of GDP per capita. The negatively moderated relationship shown may be due to several probable reasons. Though GDP per capita indicates the economic growth of a country, the benefits of the development may not have reached the common public uniformly. As noted in legal frameworks for eHealth by WHO[4], even though a country is highly developed, still there will be a majority who will not have access to eHealth tools. The tools may not reach the people who really need them and will only be used by a certain class of people in the society (digital divide). The public who do not have access to IT, could suffer from poor healthcare access[10]. Also, it is found that developed countries tend to be less confident in the healthcare system, thus less confidence in eHealth systems. Thus, investing more in ICT for healthcare may not attract public to eHealth, unless the public confidence on the system is simultaneously improved[19] and a uniform accessibility to the public is created.

\section{Conclusion}

\subsection{Limitations}

Use of secondary data obtained from various sources can be considered as a limitation in carrying out this research. However, it is not feasible to collect primary data from more than 50 countries considering the budgetary and human resource constraints. Since these data used are collected from some reputable organizations such as WHO, WEF, UN it can be ensured that these data are collected using stringent measures and statistical methods have been used to ensure the validity and reliability of these data. Moreover, several researchers had used similar data for their studies[10, 20].

In this study we considered only ISR as an indicator for standard of health. Thus, to obtain more generalized and robust results, it would be better to take some other health outcomes too for consideration. Also, in the self-developed measure, rather than identifying whether there is an eHealth policy or not it would have been better if the level of implementation was known. However, such data are available only for some countries and even those are indicating only whether partially or fully implemented.

We considered only the countries having data for all the predictors and moderator variables. Thus, we could only consider 55 countries in this cross sectional study. For example, many African countries had to be removed from the consideration due to this reason. In this study, we have used 4 independent variables including the moderators. Therefore, the sample size of 40 is adequate to capture fairly small $\mathrm{R}^{2}$ values at a significant level of $0.05[35]$. Despite these three limitations, the findings are useful in assessing the moderating effect of environment factors on the relationship of eHealth development and health standard.

\subsection{Implications and Future Research}

As theoretical contribution of this study, we can identify; (1) Contribution made to theoretical discourse of RBV's resource complementary perspective. In previous studies, it is considered that IS innovation and deployment have direct effect on 
outcomes. However, our study maintains that having a specific resource can improve the outcome rather than having only the predictors (application of IS). (2) Contribution made to the knowledge base of IT-healthcare standard in assessing the influence of environmental factors in national level on the relationship between eHealth development and health outcomes (ISR).

As practical contribution, this study assists practitioners, policy makers and administrators to understand the reasons for various levels of health outcomes and use these findings in development of policy and in management of complementary assets. Getting negative interaction effects indicate that administrators should pay more attention on these complementary resources and should learn from the mistakes made before.

The findings of our research have implications for future research. First, while we show that macro-economic stability, GDP per capita and institutions have interaction effect on eHealth development and ISR, new complementary assets could be introduced to the model. For example, moderation effect of technological readiness and technological innovation can be examined. Second, panel dataset could be used to examine the effect of leads and lags between predictors, moderators and dependent variables. Third, rather than using only ISR to measure the health outcome, new combined measures could be introduced. Specially, since many developed nations are having a high ISR, a new measure could be introduced to indicate national health outcomes. Finally, self-developed eHealth development measure can be further improved by including more items to capture relevant data. However, there should be more complete national eHealth data to achieve that.

In conclusion, this study provides a new perspective to the relationship between eHealth development and national health outcomes by introducing complementary assets, namely, macro-economic stability, GDP per capita and institutions. Through this study, we found the moderating effect of environmental factors on the relationship between eHealth development and national health outcomes. This will be helpful to understand how IS innovations should be managed and to understand the influence of IS innovations in healthcare on health outcomes (ISR) in reference to complementary assets.

\section{References}

1. Kohn, L.T., Corrigan, J., Donaldson, M.S.: To err is human: building a safer health system, vol. 6. Natl. Academy Pr. (2000)

2. America, I.o.M.C.o.Q.o.H.C.i.: Crossing the quality chasm: A new health system for the 21st century. National Academies Press (2001)

3. Wu, S., et al.: Systematic review: impact of health information technology on quality, efficiency, and costs of medical care. Annals of Internal Medicine 144(10), 742-752 (2006)

4. World-Health-Organization, Global Observatory for eHealth (GOe) (2006), http: / / www. who.int/kms/initiatives/ehealth/en

5. Berwick, D.M.: What 'patient-centered'should mean: confessions of an extremist. Health Affairs 28(4), w555-w565 (2009) 
6. Kauffman, R.J., Kumar, A.: Impact of information and communication technologies on country development: Accounting for area interrelationships. International Journal of Electronic Commerce 13(1), 11-58 (2008)

7. Lohr, S.: Doctors Raise Doubts on Digital Health Data. New York Times (2009)

8. Teece, D.J.: Profiting from technological innovation: Implications for integration, collaboration, licensing and public policy. Research Policy 15(6), 285-305 (1986)

9. Srivastava, S.C., Thompson, S.: E-Government, E-Business and National Economic Performance (2010)

10. Mithas, S., Khuntia, J., Agarwal, R.: Information Technology and Life Expectancy: A Country-Level Analysis (2009)

11. Teece, D.J.: The Strategic Management of the Oxford Handbook of Strategy, p. 138 (2006)

12. Shaw, B.: Innovation and new product development in the UK medical equipment industry. International Journal of Technology Management 15(3), 433-445 (1998)

13. Barney, J., Wright, M., Ketchen, D.J.: The resource-based view of the firm: Ten years after 1991. Journal of Management 27(6), 625-641 (2001)

14. Ravichandran, T., Lertwongsatien, C.: Effect of information systems resources and capabilities on firm performance: A resource-based perspective. Journal of Management Information Systems 21(4), 237-276 (2005)

15. Porter, M.E., Schwab, K.: The Global Competitiveness Report 2008-2009 (2009)

16. Car, J., et al.: The impact of eHealth on the quality and safety of healthcare. In: A Systemic Overview and Synthesis of the Literature. Imperial College London and The University of Edinburgh, London (2008)

17. Black, A.D., et al.: The impact of eHealth on the quality and safety of health care: a systematic overview. PLoS Medicine 8(1), e1000387 (2011)

18. Stroetmann, K.A., et al., eHealth is Worth it: The economic benefits of implemented eHealth solutions at ten European sites. European Commission (2006)

19. Bagchi, K., Udo, G., Kesh, M.: An Empirical Study Identifying the Factors that Impact eHealth Infastructure and eHealth Use (2005)

20. Srivastava, S.C., Teo, T.S.H.: What facilitates e-government development? A crosscountry analysis. An International Journal on Electronic Government 4(4), 365-378 (2007)

21. Groot, W., Van Den Brink, H.M.: The health effects of education. Economics of Education Review 26(2), 186-200 (2007)

22. Diaz, J.A., et al.: Patients' use of the Internet for medical information. Journal of General Internal Medicine 17(3), 180-185 (2002)

23. Kiecolt, K.J., Nathan, L.E.: Secondary analysis of survey data1985. Sage Publications, Inc. (1985)

24. Woszczynski, A.B., Whitman, M.E.: The problem of common method variance in IS research. The Handbook of Information Systems Research, 66-77 (2004)

25. World Health Organization (WHO), W.H.S., WHO Press, Geneva. and A.o.(2011), http: / /www. who.int/whosis/whostat/2011/en/index.html

26. United Nations Department of Economic and Social Affairs (2008). United Nations E-Government Survey (2008), http://unpan1.un.org/intradoc/groups/ public/documents/un/unpan028607.pdf

27. WITSA, Digital Planet 2008: The Global Information Economy. Arlington: WITSA (2008)

28. Bankole, F.O., Kweku, M.O., Brown, I.: Exploring the Impacts of ICT Investments on Dimensions of Human Development in Different Contexts: A Regression Splines Analysis. In: Proceedings of SIG GlobDev Fourth Annual Workshop (2011) 
29. Krishnan, S., Teo, T.: Engaging Citizens in Managing Electronic Government Service Quality: A Country-Level Analysis (2011)

30. Krishnan, S., Teo, T.S.H.: The Effect Of Information Systems Capabilities On Sustainability: A Country-Level Analysis (2011)

31. Ngwenyama, O., et al.: Is There A Relationship Between ICT, Health, Education And Development? An Empirical Analysis of five West African Countries from 1997-2003. The Electronic Journal of Information Systems in Developing Countries 23(0) (2006)

32. Dutta, S., Mia, I.: Global Information Technology Report 2008-2009. World Economic Forum (2010)

33. Gujarati, D.N.: Basic Econometrics, 4th edn. McGraw-Hill, New York (2003)

34. Gujarati, D.N., Porter, C.: Basic Econometrics, Boston. McGraw-Hill International Edition, 5th edn., pp. 260-261, 338 (2009)

35. Hair Jr., J., Black, W.C., Babin, B.J., Anderson, R.E., Tatham, R.L.: Multivariate data analysis (2006)

36. Husted, B.W., Instituto Technologico y de Estudios.: Wealth, culture, and corruption. Journal of International Business Studies, 339-359 (1999)

37. Frazier, P.A., Tix, A.P., Barron, K.E.: Testing moderator and mediator effects in counseling psychology research. Journal of Counseling Psychology 51(1), 115 (2004)

38. Aiken, L.S., West, S.G., Reno, R.R.: Multiple regression: Testing and interpreting interactions1991. Sage Publications, Inc. (1991)

39. West, S.G., Aiken, L.S., Krull, J.L.: Experimental personality designs: Analyzing categorical by continuous variable interactions. Journal of Personality 64(1), 1-48 (1996)

40. Cohen, J., Cohen, P., West, G.S., Aiken, L.S.: Applied multiple regression/correlation analysis for the behavioral sciences (2003) 


\section{Appendix: Countries Considered in this Study}

$\begin{array}{lll}\text { Argentina } & \text { India } & \text { Poland } \\ \text { Australia } & \text { Indonesia } & \text { Portugal } \\ \text { Austria } & \text { Ireland } & \text { Romania } \\ \text { Bangladesh } & \text { Israel } & \text { Senegal } \\ \text { Belgium } & \text { Italy } & \text { Singapore } \\ \text { Brazil } & \text { Japan } & \text { Slovakia } \\ \text { Bulgaria } & \text { Jordan } & \text { Slovenia } \\ \text { Cameroon } & \text { Korea } & \\ \text { Canada } & \text { Kupublic of) } & \text { Spain } \\ \text { China } & \text { Malaysia } & \text { Sri Lanka } \\ \text { Colombia } & \text { Mexico } & \text { Sweden } \\ \text { Czech } & & \text { Switzerland } \\ \text { Republic } & \text { Morocco } & \text { Thailand } \\ \text { Denmark } & \text { Netherlands } & \text { Turkey } \\ \text { Egypt } & \text { New Zealand } & \text { Kingdom } \\ \text { Finland } & \text { Norway } & \text { United } \\ \text { France } & \text { Pakistan } & \text { Viet Nam } \\ \text { Germany } & \text { Panama } & \text { Zimbabwe } \\ \text { Greece } & \text { Peru } & \\ \text { Hungary } & \text { Philippines } & \\ & & \end{array}$

